\section{Estudo \\ cabebate}

em Cestão

Plamejamento
Revista Estudo \& Debate, Lajeado, v. 27, n. 2, 2020. ISSN 1983-036X

DOI: http://dx.doi.org/10.22410/issn.1983-036X.v27i2a2020.2558

\title{
DIFERENCIAIS DE RENDIMENTOS DO TRABALHO NA AGROPECUÁRIA BRASILEIRA: UMA ABORDAGEM POR REGRESSÓES QUANTÍLICAS
}

\author{
Luís Abel da Silva Filho ${ }^{1}$, Edicléia de Olivieira Silva ${ }^{2}$, Bruno César Brito Miyamoto ${ }^{3}$
}

\begin{abstract}
Resumo: As transformaçóes registradas na agropecuária brasileira nos últimos anos foram substancialmente elevadas, no que diz respeito às formas de produção vis-à-vis às de trabalho. Assim sendo, este artigo visa analisar os diferenciais de rendimentos do trabalho na agropecuária brasileira - a partir dos efeitos das características socioeconômicas e demográficas dos ocupados, bem como do perfil dos postos de trabalho - ao longo da distribuição condicional dos salários. Recorreu-se a uma análise empírica, a partir do uso de Regressões Quantílicas, e o uso dos microdados da Relação Anual de Informações Sociais - RAIS da secretaria da previdência social e emprego do Ministério da Economia - ME. Os resultados mostram que os efeitos das características socioeconômicas e demográficas dos ocupados impactam sobre os rendimentos do trabalho ao longo de toda a distribuição condicional dos salários e em todos os anos em apreço.
\end{abstract}

Palavras-chave: Diferenciais de rendimentos. Agropecuária. Brasil.

\section{DIFFERENTIALS OF LABOR INCOME IN BRAZILIAN AGRICULTURE: AN APPROACH BY QUANTILIC REGRESSIONS}

\begin{abstract}
The changes registered in Brazilian agriculture in recent years have been substantially high, with regard to forms of production vis-à-vis those of work. Therefore, this article aims to analyze the differentials of income from work in Brazilian agriculture - from the effects of the socioeconomic and demographic characteristics of the employed, as well as the profile of jobs - over the conditional distribution of wages. An empirical analysis was used, based on the use of Quantile Regressions, and the use of microdata from the Annual List of Social
\end{abstract}

1 Professor Adjunto do Departamento de Economia a Universidade Regional do Cariri - URCA; Bacharel em Economia pela Universidade Regional do Cariri - URCA; Mestre em Economia pela Universidade Federal do Rio Grande do Norte - UFRN; Doutor em Ciências Econômicas pelo Instituto de Economia da Universidade Estadual de Campinas - UNICAMP.

2 Bacharela em Economia pela Universidade Regional do Cariri - URCA.

3 Professor do Instituto Federal de Educaçáo, Ciência e Tecnologia do Rio Grande do Sul - IFRS; Bacharel em Administração pela Universidade Estadual Paulista Júlio de Mesquita Filho; Mestre e Doutor em Desenvolvimento Econômico pelo Instituto de Economia da Universidade Estadual de Campinas UNICAMP. 
Information - RAIS of the Social Security and Employment Secretariat of the Ministry of Economy - ME. The results show that the effects of the socioeconomic and demographic characteristics of the employed have an impact on income from work throughout the conditional distribution of wages and in all the years under consideration.

Keywords: Income differentials. Agriculture and livestock. Brazil.

\section{Consideraçóes Iniciais}

As disparidades de renda do trabalho no Brasil são substancialmente elevadas e se acentuam entre setores de atividade econômica, região de ocupação, posição na ocupação, formalidade ou informalidade dos postos de trabalho, bem como pelas características socioeconômicas e demográficas dos ocupados dentro e entre os setores (COELHO \& CORSEUILL, 2002; HOFFMANN \& SIMÃO, 2005; MATOS \& MACHADO, 2006; BATISTA \& CACCIAMALI, 2009; HOFFMANN, 2011; FREGÚGLIA \& PROCÓPIO, 2013). Assim sendo, compreende os níveis de desigualdades salariais no mercado de trabalho brasileiro requer um exercício consistente de análise do mercado de trabalho, onde se possa reduzir o viés setorial, regional de vínculo (formal/informal) dos postos de trabalho e, com isso, ter uma análise sucinta das questôes inerentes às diferenças de renda.

Muitos são os estudos que já trataram das disparidades salariais brasileiras, considerando-se os efeitos da raça/cor, tipo de vínculo, setor de ocupação, idade, sexo, bem como os efeitos da mecanização das atividades agropecuárias (STADUTO, 2002; SANTOS et al., 2010; CASARI \& BACHA, 2010). Todas as características socioeconômicas e demográficas apresentam efeitos sobre as disparidades de renda do trabalho. Assim sendo, é possível afirmar pela seletividade laboral no país, como forma de remunerar melhor os ocupados em setores de atividade econômica e com características que se sobrepóem a maioria da força laboral ocupada, sendo que somente a elevação da escolaridade da força de trabalho consegue reduzir os efeitos discriminarão de outras características.

Nessa perspectiva, estudar somente um setor de atividade econômica e com vínculo laboral dentro do âmbito da formalidade, faz com que se reduzam os vieses que podem influenciar nos diferenciais de rendimentos do trabalho, mas que não possam ser comparados, dado a própria natureza do vínculo empregatício. Assim sendo, estudar as disparidades de renda entre os ocupados formais na agropecuária brasileira é um exercício consistente de se conhecer as disparidades salariais intrasetoriais, a partir de um conjunto de características socioeconômicas e demográficas dos indivíduos.

Assim sendo, este artigo visa analisar as disparidades salariais entre a força de trabalho ocupada na agropecuária brasileira, nos pontos mais elevados da distribuiçáo da renda do trabalho (mediana, $3^{\circ}$ quartil e $9^{\circ}$ percentil) entre os anos de 2000, 2005, 2010 e 2015, a partir do emprego de regressóes quantílicas. É pertinente um estudo desta natureza, uma vez que a maioria dos estudos que tratam da agropecuária brasileira abordam os efeitos destas características considerando as especificidades dos postos de trabalho agropecuário no âmbito da construçáo de vínculos formais ou informais, permanente ou temporário, dentre outros (BALSADI \& GRAZIANO SILVA, 2008; CUNHA, 2009; SILVA FILHO, 2013), sem, contudo, abordar especificamente o setor formal, que, deve ser o de melhores 
condições de exercício das atividades laborais, bem como de melhores retornos salarias a força de trabalho ocupada.

Para o alcance do objetivo proposto neste artigo, ele encontra-se, assim estruturado: além destas considerações iniciais; a segunda seção aborda uma revisão da literatura empírica acerca das desigualdades de renda do trabalho no Brasil; na terceira seção são apresentados os procedimentos metodológicos adotados; na quarta seção, têm-se as estatísticas do emprego formal na agropecuária brasileira; na quinta seção, apresentem-se os resultados e discussóes; e, por último, na sexta seção, tecem-se as consideraçóes finais e as perspectivas de novas abordagens.

\section{Desigualdade de renda do trabalho no Brasil: uma revisão da literatura empírica}

$\mathrm{O}$ estudo sobre a desigualdade de renda no Brasil vem sendo um tema recorrente na literatura econômica. Os diferenciais de rendimentos existentes no mercado de trabalho brasileiro, conforme Silva Filho et al. (2017), são, em parte, resultado das características socioeconômicas e demográficas dos indivíduos. Contudo, estas disparidades de renda podem ser fortemente influenciadas, tanto pelas mudanças estruturais ocorridas na economia, como também pela reorganização interna dos setores produtivos.

A grande maioria dos estudos sobre os diferenciais de rendimentos do trabalho sinalizam que a variável educação desempenha papel significativo na determinação dos diferenciais de salários dos trabalhadores. A educação, ainda que não única, é o fator que melhor explica a desigualdade de renda entre os indivíduos. A relação é direta: quanto maior for o nível educacional dos trabalhadores, maior será os seus retornos salarias, conforme visto nos trabalhos de Ramos \& Vieira (2001), Soares (2001) e Ney \& Hoffmann (2003), dentre outros.

Analisando uma investigação empírica do impacto do capital humano na distribuição de salários dos trabalhadores brasileiros no período de 1992-2002, por meio de estimaçóes por regressôes quantílicas, Justo (2006), mostra a importância desempenhada pela educação sobre os diferenciais salariais. Os principais resultados apontam crescimento da desigualdade nas taxas de retorno à educação, sendo este atributo melhor remunerado pelo mercado de trabalho por associa-lo à produtividade. Embora as taxas de retorno tenham sido mais altas para os quantis superiores da distribuição, melhorias nas características de adoção e educação ocorrem, sendo sentidas mais fortemente pelos indivíduos situados nos quantis inferiores. Além disso, foi possível verificar redução da desigualdade de renda entre os empregados no setor agrícola e nos demais setores de atividade, com destaque especial para os situados nos quantis mais elevados (superiores) da distribuição.

Estudos recentes mostram que além da educação, existem outros fatores de peso relevante na explicação da desigualdade de renda verificado no mercado de trabalho. Conforme Soares (2009), o sexo, a raça/cor e região geográfica aparecem com frequência como determinantes da desigualdade de renda. Entre esses estudos, destaca-se o de Vilela et al. (2012), os quais analisaram o diferencial de rendimentos por cor e sexo no Brasil, focando nas diferentes geraçóes do mercado de trabalho. Com o fito de investigar essa relação para os diferentes quantis da renda, utilizaram-se a técnica de regressóes quantílicas. 
Por um lado, os resultados obtidos pela regressão confirmaram que existe discriminação salarial contra mulheres e negros no mercado de trabalho brasileiro (sendo mais intensas por sexo). Por outro lado, essas discriminaçóes são menores entre as geraçóes mais jovens quando comparadas as mais velhas, confirmando a ideia que a nova geração está se deparando com um mercado de trabalho cada vez melhor "mais igualitário", devido à melhora no nível de escolaridade.

Machado et al. (2008), investigando o diferencial de rendimentos entre o setor formal e informal do mercado de trabalho no Brasil nos de 1992, 1998 e 2004, utilizando dados da Pesquisa Nacional por Amostra de Domicilio (PNAD), a partir do uso de regressão quantílica, contataram que as variáveis educação, idade e experiência são também fatores importantes para explicar os diferenciais de rendimentos dos trabalhadores entre os dois setores.

Ademais, a região geográfica também se mostra importante para explicar as disparidades de renda. A partir da utilização de regressóes quantílicas, Silveira Neto \& Campêlo (2003) fornecem evidencias sobre as disparidades regionais de renda no Brasil metropolitano. O principal resultado apontado neste estudo mostra que as disparidades regionais afetam os mais pobres das regióes metropolitas do Nordeste brasileiro. Ou seja, os resultados apontam a existência de grandes variaçóes das desigualdades regionais por quantis de renda: as maiores são registradas para os quantis inferiores (mais pobres) e os menores para os quantis superiores (mais ricos). Isto é, as regióes economicamente mais desenvolvidas, além de apresentarem menores desigualdades salariais entre os ocupados, contratam com melhores salários, conforme Savedoff (1990).

\section{Procedimentos Metodológicos}

Esta seção busca apresentar os procedimentos metodológicos adotados para o alcance do objetivo proposto.

\subsection{Base de dados e recorte temporal}

Neste artigo, recorreu-se aos microdados da Relaçáo Anual de Informaçóes Sociais da secretaria da previdência social e do emprego do Ministério da Economia (RAIS-ME). Embora a base de dados seja um Censo do emprego formal no Brasil, utilizou-se aqui apenas uma amostra de dados para cada um dos anos. A escolha pelo uso de amostra se deu pelo fato de alguns dos órgãos empregadores não enviar todas as informaçóes correspondentes ao mesmo indivíduo, por exemplo, faltando alguma informação do ocupado. Dessa forma, para não provocar viés nas estimativas, deixaram-se na amostra apenas os ocupados que tinha todas as informaçóes utilizadas neste estudo. Depois de todos os recortes, os anos de 2000, 2005 e 2010 tiveram uma amostra superior a 80\% da população censitária da RAIS, sendo que no ano de 2015 registrou-se redução na amostra, porém ficando em aproximadamente $50 \%$ de toda a população censitária da RAIS. 


\subsection{Modelo empírico}

Objetiva-se analisar os efeitos das características socioeconômicas e demográficas sobre os diferenciais de rendimentos do trabalho na agropecuária brasileira, a partir do uso de Regressóes Quantílicas. A escolha pelo método se deu, devido ao propósito de analisar estes efeitos na distribuição condicional da renda do trabalho formal, uma vez que a existência de Outliers pode provocar distorções na média. O uso de regressóes quantílicas foi proposto por Koenker \& Basset (1978), e amplamente utilizado em estudos que visam analisar os efeitos de variações nas variáveis explanatórias sobre vários pontos da distribuição de uma variável explicada (dependente). Conforme Buchinsky (1998), o uso da regressão quantílica reduz os efeitos da presença de Outliers na análise por percentil e apresenta estimativas mais adequadas, comparativamente aos Mínimos Quadrados Ordinários, que apresenta estimativas na média, apenas.

Neste estudo, a variável regressando assume a função de logaritmo natural da renda do trabalho (ln_rendatrab), a ser explicada por um conjunto de características socioeconômicas e demográficas dos postos de trabalho e dos indivíduos ocupados (sexo, idade, idade ${ }^{2}$, tamanho do estabelecimento, faixa de tempo no emprego, escolaridade e região de ocupação). Busca-se estimar os efeitos de cada uma destas características sobre os percentis da distribuição da renda do trabalho na agropecuária brasileira.

As estimaçóes neste artigo se deram a partir da mediana, terceiro quartil e do nonagésimo percentil de $y_{i}(50,75,90)$ distribuição de renda, objetivando analisar as disparidades de renda do trabalho nos pontos mais elevados da distribuição condicional da renda..

Assim sendo, se $\left(x_{i} y_{i}\right), i=1, \ldots, n$, representa uma amostra aleatória da força de trabalho formalmente ocupada na agropecuária brasileira, em que o $x_{i}$ assuma a função de um vetor de ( $K x 1)$ variáveis explicativas (características socioeconômicas e demográficas) e $y_{i}$ é variável a ser explicada em seus vários pontos da distribuição condicional da renda, em que o $\theta$ - ésimo quantil da variável explicada $y_{i}$ se apresenta como:

$F^{-1}=\inf \{y: F(y) \geq 0\}$

Na equação $1 F$ é descrito como uma função de distribuição não condicionada de $y$ . Havendo relação de linearidade entre a variável regressando y e suas variáveis regressoras $x$, tem-se a representação matemática da equação, conforme em 2 :

$y_{i}=x_{i}^{\prime} \beta+\mu_{i}$

Assim, em (2), $\beta$ corresponde a um vetor de parâmetros estimados (a partir das características socioeconômicas e demográficas dos postos de trabalho e dos indivíduos ocupados) nos percentis de $y_{i}(50,75,90)$ definidos a partir dos quantis da distribuição condicionais dos erros, expressa em 3 : 
$\operatorname{Pr}\left(y_{i} \leq \frac{y}{x_{i}}\right)=F_{\mu \theta}\left(y-\frac{x^{\prime} \beta_{\theta}}{x_{i}}\right), 1=1, \ldots, n$

Diante da representação matemática da equação 3 , a estimação da regressão quantílica pode ser definida da forma, a saber:

$Q_{\theta}\left(\frac{y_{i}}{x_{i}}\right)=x_{i}^{\prime} \beta_{\theta}+F_{\mu}^{-1}(\theta)$

Nos pontos da distribuição da variável explicada $y_{i}(50,75,90)$ devem ser lidos como incondicionais. Com isso, apresenta-se a solução de um problema de maximização. Todavia, o estimador de $\beta_{\theta}$ na equação matemática de 4 necessita, assim, ser definida a partir da função objetivo, apresentada em 5 :

$$
\min \frac{1}{n} \sum_{i: y_{i} \geq x_{i} \beta} \theta\left|y_{i}-x_{i}\right| \beta+\sum_{i: y_{i} \geq x_{i} \beta} 1-\theta\left|y_{i}-x_{i}\right| \beta=\min \frac{1}{\beta} \sum_{i=1}^{n} \rho_{\theta}\left(y_{i}-x_{i} \beta\right)
$$

Na regressão quantílica foi estimada a minimização de valores absolutos das variáveis, ao contrário do que se estima em Mínimos Quadrados Ordinários. Assim, o método definido, em seguida, define a função condicional de cada um dos quantis da variável regressando $y$, ante a matiz $x$ de variáveis regressoras, definida em 6 :

$Q_{y i}\left(\frac{\theta}{x}\right)=X \beta(\theta)$, onde $\theta=[0,1]$

Cada um dos percentis de $y_{i}(50,75,90)$, é captado o efeito das variáveis regressoras, contidas em $x$ sobre $y$ (log_rendatrab), em cada ponto de $y$ aqui analisado. Com isso, busca-se explicar os efeitos das características socioeconômicas e demografias dos postos de trabalho e dos indivíduos na agropecuária sobre a renda auferida. A equação matemática estimada neste artigo segue a definição abaixo:

$$
\begin{aligned}
\ln w_{i}=\beta_{1}^{\theta}+ & \beta_{2}^{\theta} \operatorname{sex}+\beta_{3}^{\theta} \exp +\beta_{4}^{\theta} \exp ^{2}+\beta_{5}^{\theta} \text { estab } 1+\beta_{6}^{\theta} \text { estab } 2+\beta_{7}^{\theta} \text { estab } 3 \\
& +\beta_{8}^{\theta} \text { temp } 1+\beta_{9}^{\theta} \text { temp } 2+\beta_{10}^{\theta} \text { temp } 3+\beta_{11}^{\theta} \text { temp } 4+\beta_{12}^{\theta} \text { temp } 5+\beta_{13}^{\theta} \text { esc } 1 \\
& +\beta_{14}^{\theta} \operatorname{esc} 2+\beta_{15}^{\theta} \text { esc } 3+\beta_{16}^{\theta} \text { reg } 1+\beta_{17}^{\theta} \text { reg } 2+\beta_{18}^{\theta} \text { reg } 3+\beta_{19}^{\theta} \text { reg } 4 \\
& +\varepsilon_{\theta i}
\end{aligned}
$$

Em que, os parâmetros a serem estimados para os ocupados na agropecuária são representados por $\beta_{i}^{\theta}, \ldots, \beta_{n}^{\theta}$ e explicam o logaritmo da renda do trabalho $\left(\ln w_{i}\right)$ em cada quartil e nos anos específicos. Além disso, $\varepsilon_{\theta i}$, estes, correspondem aos erros residuais do modelo. $\beta_{2}^{\theta}$ sex é o sexo do ocupado; $\beta_{3}^{\theta} \exp$ e $\beta_{4}^{\theta} \exp { }^{2}$ correspondem a idade, usada como proxy de experiência; $\beta_{5}^{\theta}$ estab1, $\beta_{6}^{\theta}$ estab2, $\beta_{7}^{\theta}$ estab3, são os estabelecimentos de pequeno, médio e grande portes, respectivamente (microporte é a 
categoria de referência); $\beta_{8}^{\theta}$ temp $1, \beta_{9}^{\theta}$ temp $2, \beta_{10}^{\theta}$ temp $3, \beta_{11}^{\theta}$ temp $4, \beta_{12}^{\theta}$ temp 5 , corresponde ao tempo de permanência no emprego, sendo respectivamente, mais de um ano e até dois anos, mais de dois e até três anos, mais de três e até cinco anos, mais de cinco e até dez anos, e, mais de dez anos (até um ano é a categoria de referência); $\beta_{13}^{\theta} e s c 1$, $\beta_{14}^{\theta} e s c 2, \beta_{15}^{\theta} e s c 3$, representam, respectivamente, os níveis de escolaridade a saber: ensino fundamental completo e médio incompleto, ensino médio completo e superior incompleto, superior completo (sem instrução e ensino fundamental incompleto foi a categoria de referencia); $\beta_{16}^{\theta}$ reg $1, \beta_{17}^{\theta}$ reg $2, \beta_{18}^{\theta}$ reg $3, \beta_{19}^{\theta}$ reg 4 , sendo, respectivamente: Norte, Sudeste, Sul e Centro-oestes (Nordeste é a categoria de referência); $\varepsilon_{\theta i}$ representa o resíduo amostral.

\section{Estrutura do emprego formal agropecuário no Brasil - uma análise recente}

A distribuição do emprego formal agropecuário brasileiro segue uma tendência relativamente constante ao longo dos anos em análise. Com exceção das áreas de expansão das atividades agropecuárias, dado, sobretudo pela evolução e ocupação das atividades de exportaçóes, sobretudo em áreas de expansão da fronteira agrícola nacional, o comportamento do mercado de trabalho neste setor segue uma tendência de distribuiçáo dos postos de trabalho nas tradicionais áreas e produção agropecuária do país.

Como pode ser observado na figura 01 , expande-se a quantidade de pontos que representam os postos formais de trabalho na agropecuária entre os anos de 2000 e de 2015. Pode-se destacar, visivelmente, a expansão de postos formais de trabalho na fronteia agrícola nacional dado pela ocupação dos estados denominados de MATOIPBA - Maranhão, Tocantins, Piauí e Bahia. Nas demais regiōes permanecem os padrões de concentração, não sendo possível visualizar mudanças substanciais na distribuição dos ocupados. 
Figura 01: distribuição dos postos formais de trabalho na agropecuária nos municípios brasileiros - 2000/2005/2010/2015
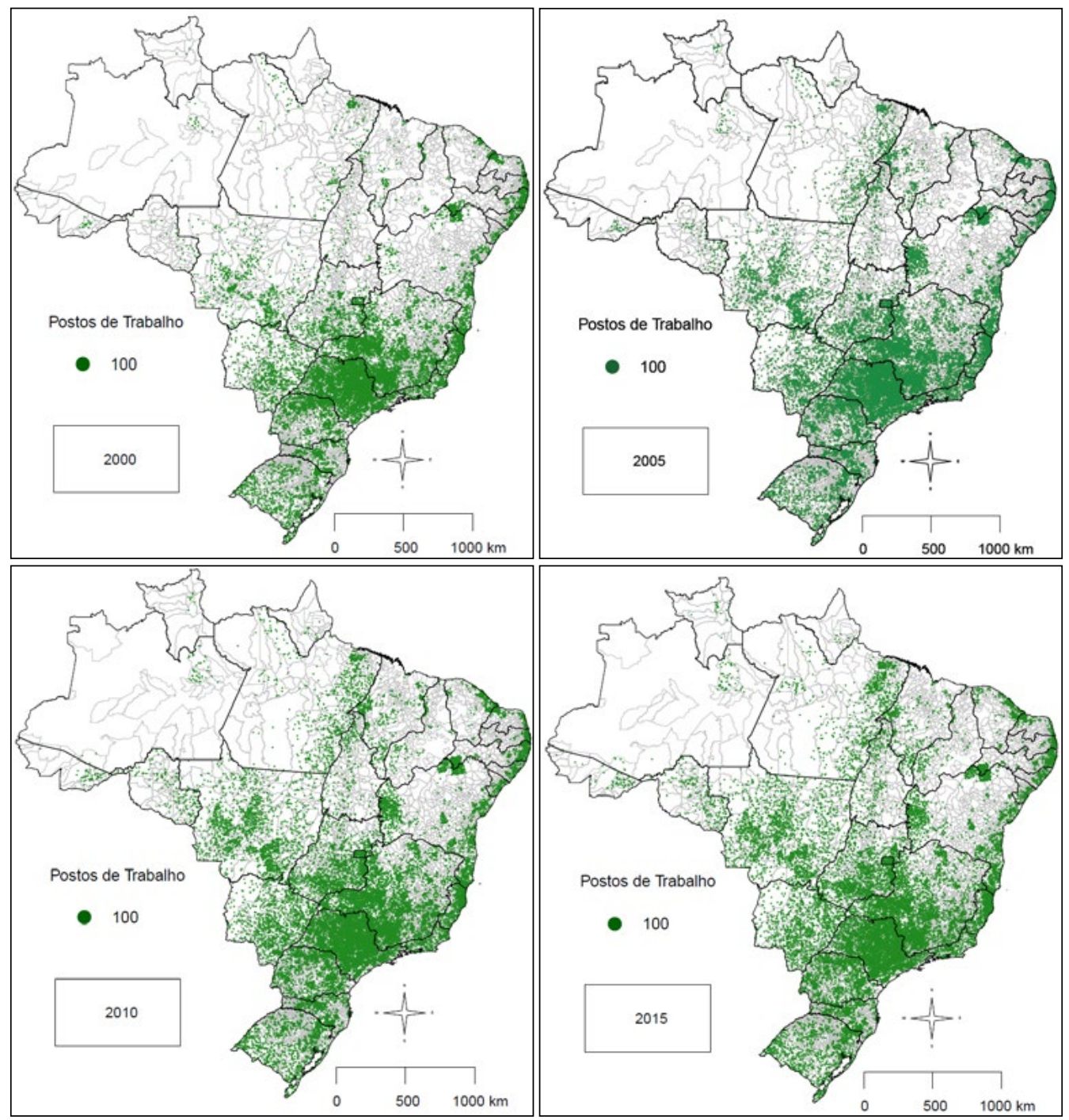

Fonte: elaboração dos autores a partir dos microdados da RAIS e do uso do Software R.

Por região, chama atenção a forte concentração na área litorânea no Nordeste, bem como na regiáo do vale do Submédio do Sáo Francisco em todos os anos em apreço. Além disso, a ocupação nas demais áreas do Nordeste ficou restrita ao avanço de postos de trabalho na região do MATOPIBA. Nas demais regióes, destaca-se apenas o crescimento da ocupação quando se compara o ano 2000 aos demais anos. Nas demais regiôes do país parecem manter a distribuição dos postos de trabalho sem alteração na escala geográfica visível. 
No que diz respeito à renda média dos ocupados na agropecuária por municípios brasileiros, a figura 01 classifica essas unidades subnacionais pela renda média dos ocupados neste setor com distribuição em mapas anuais do recorte analisado. Pela coloração dos mapas, de acordo com a legenda de renda média, é possível perceber que as áreas de produção agropecuária para exportaçóes sejam de grãos seja do setor de animais de cortes, a renda média dos ocupados formais é mais elevada, convergindo com outros estudos já realizados no setor (SANTOS \& CASARI, 2014).

Figura 02: classificação dos municípios de acordo com a renda média do trabalho na agropecuária brasileira - 2000/2005/2010/2015.
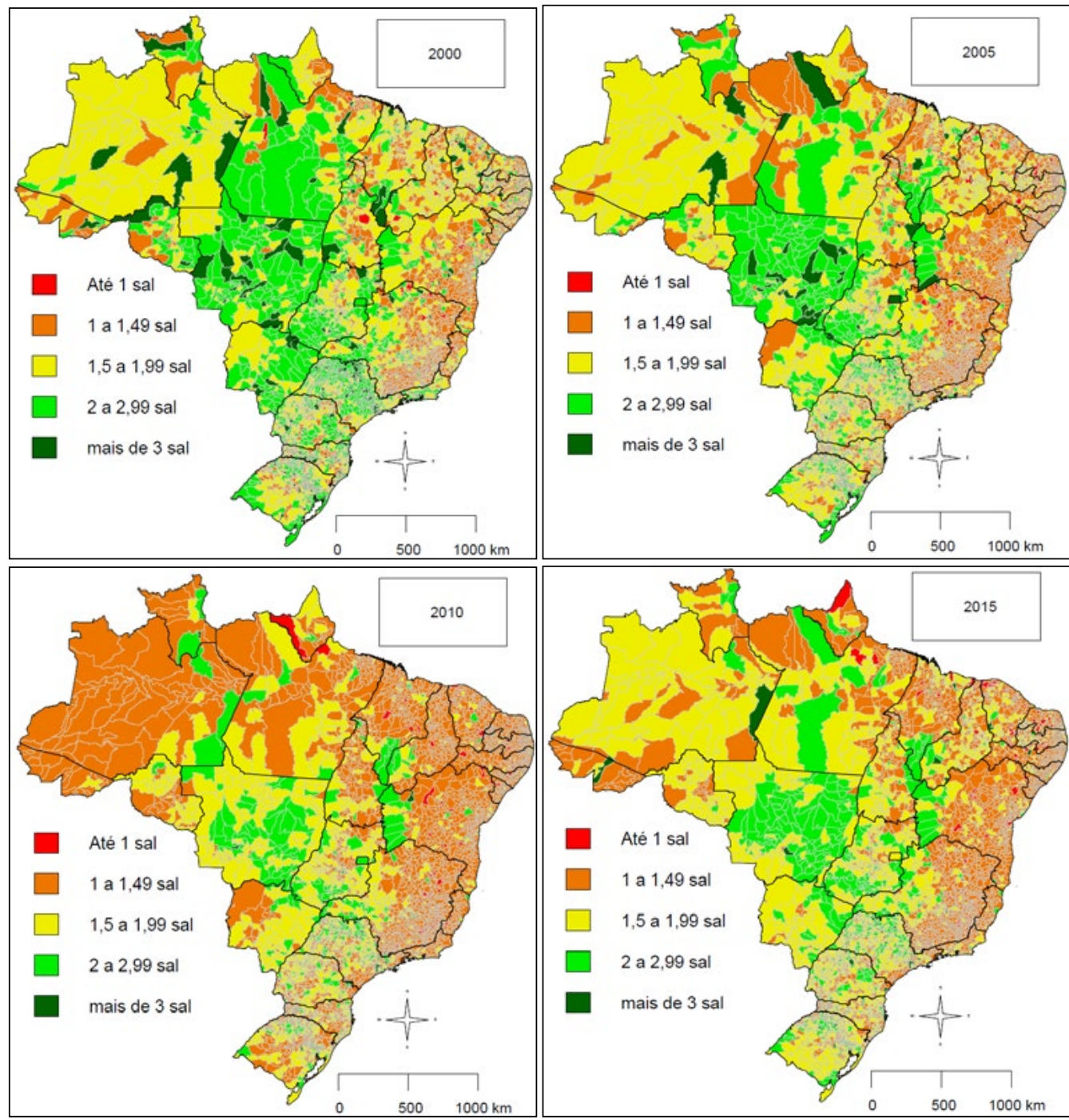

Fonte: elaboração dos autores a partir dos microdados da RAIS e do uso do Software R. 
Além disso, é possível visualizar redução na renda média dos ocupados formais na agropecuária ao longo dos anos, dado pela redução da "mancha verde" - municípios de maior renda média no país - entre o ano 2000 e o ano de 2015. Essa redução pode resultar da elevação de postos de trabalho com remuneração média menor, tendência observada nos empregos brasileiros. Em termos reais, sabe-se que houve ganhos salariais, porém a figura mostra os valores em salários mínimos. Em que pese à redução no número de municípios com renda média menor, é possível destacar que a região de agropecuária de exportação, registra-se a maior renda média do trabalho nestes municípios, sugerindo que as atividades agropecuárias destinadas ao comércio exterior promovem a maior distribuição de renda no país.

No que diz respeito às características socioeconômicas e demográficas dos ocupados, plotadas na tabela 01, é possível destacar o crescimento da idade média ao longo dos anos, que no primeiro, era de 33,92 anos e em 2015 era de 36,88. Além disso, eleva-se, apesar de levemente, a participação de mulheres ocupadas, já que no primeiro ano elas ocupavam $15,55 \%$ dos postos formais de trabalho na agropecuária brasileira, elevando-se para 18,45\% no ano de 2015. Adicionalmente, destaque-se que a distribuição de postos de trabalho por tamanho dos estabelecimentos parece manter o padrão ao longo dos anos, uma vez que, somente é possível registrar alguma alteração relevante no microestabelecimento que ganha levemente participaçáo ao longo dos anos, em detrimento de perda de participação dos médios estabelecimentos, e, em menor dimensão, do grande estabelecimento. Isso pode resultar tão somente das configuraçóes técnicas das atividades agropecuárias que se dão, no mais das vezes, por um processo poupador de mão de obra, sem, contudo, implicar na redução da produção ou da propriedade produtiva.

Tabela 01: caracterização socioeconômica dos ocupados formais na agropecuária brasileira segundo o sexo - 2000/2005/2010/2015

\begin{tabular}{|c|c|c|c|c|}
\hline \multirow{2}{*}{ Variáveis } & 2000 & 2005 & 2010 & 2015 \\
\hline & Agropecuária & Agropecuária & Agropecuária & Agropecuária \\
\hline \multicolumn{5}{|c|}{ Idade média dos ocupados formais } \\
\hline Idade & 33,92 & 34,10 & 35,37 & 36,88 \\
\hline \multicolumn{5}{|c|}{ Sexo dos ocupados formais } \\
\hline Masculino & 85,45 & 84,45 & 82,29 & 81,55 \\
\hline Feminino & 14,55 & 15,55 & 17,71 & 18,45 \\
\hline \multicolumn{5}{|c|}{ Distribuiçáo dos ocupados formais por tamanho do estabelecimento } \\
\hline Micro & 49,90 & 48,66 & 49,55 & 51,73 \\
\hline Pequeno & 21,71 & 21,74 & 21,32 & 20,72 \\
\hline Médio & 15,50 & 16,90 & 16,46 & 14,76 \\
\hline Grande & 12,89 & 12,70 & 12,67 & 12,78 \\
\hline Total & 100,00 & 100,00 & 100,00 & 100,00 \\
\hline
\end{tabular}




\begin{tabular}{|c|c|c|c|c|}
\hline \multirow{2}{*}{ Variáveis } & 2000 & 2005 & 2010 & 2015 \\
\hline & Agropecuária & Agropecuária & Agropecuária & Agropecuária \\
\hline \multicolumn{5}{|c|}{ Tempo de permanência no empego formal } \\
\hline Até 1 ano & 58,40 & 61,76 & 59,46 & 52,60 \\
\hline Mais de 1 a 2 anos & 12,13 & 13,18 & 13,32 & 14,83 \\
\hline Mais de 2 a 3 anos & 7,52 & 7,00 & 7,68 & 8,42 \\
\hline Mais de 3 a 5 anos & 8,50 & 7,20 & 7,67 & 9,54 \\
\hline Mais de 5 a 10 anos & 7,94 & 6,63 & 7,40 & 8,92 \\
\hline Mais de 10 anos & 5,51 & 4,22 & 4,46 & 5,69 \\
\hline Total & 100,00 & 100,00 & 100,00 & 100,00 \\
\hline \multicolumn{5}{|c|}{ Nível de escolaridade dos ocupados formais } \\
\hline Seminstfundinc & 85,53 & 75,81 & 62,92 & 49,75 \\
\hline Fundcompmedinc & 9,74 & 16,22 & 21,70 & 24,27 \\
\hline Medcompsupinc & 3,64 & 6,78 & 13,78 & 23,59 \\
\hline Supcomp & 1,09 & 1,18 & 1,55 & 2,33 \\
\hline Mestrado & 0,00 & 0,00 & 0,04 & 0,05 \\
\hline Doutorado & 0,00 & 0,00 & 0,01 & 0,02 \\
\hline Total & 100,00 & 100,00 & 100,00 & 100,00 \\
\hline \multicolumn{5}{|c|}{ Distribuiçáo dos ocupados formais por regiáo geográfica } \\
\hline $\mathrm{NO}$ & 2,00 & 4,11 & 4,62 & 6,10 \\
\hline $\mathrm{NE}$ & 12,69 & 16,49 & 16,08 & 16,13 \\
\hline SE & 57,41 & 50,66 & 48,30 & 43,90 \\
\hline SU & 16,18 & 14,89 & 14,70 & 15,40 \\
\hline $\mathrm{CO}$ & 11,71 & 13,86 & 16,31 & 18,47 \\
\hline Total & 100,00 & 100,00 & 100,00 & 100,00 \\
\hline \multicolumn{5}{|c|}{ Renda média no emprego formal agropecuário } \\
\hline Rendatrab & $1.061,80$ & $1.159,48$ & $1.455,71$ & $1.712,98$ \\
\hline
\end{tabular}

Fonte: elaboração do autor a partir dos microdados da RAIS, 2019.

No que diz respeito ao tempo de permanência no emprego, é possível registrar que a rotatividade mantem-se elevada no setor agropecuário, sendo que, em todos os anos, mais de $50 \%$ da mão de obra ocupada deixaram seus postos de trabalho em menos de um ano. Além disso, é relevante destacar que os que ficaram ocupados por mais de 10 anos no mesmo emprego eram relativamente minoria entre os ocupados, uma vez que este percentual oscilou entre 5,51\%, no ano 2000, e, 5,69\%, no ano de 2015. A agropecuária é caracterizada por apresentar elevada rotatividade nos postos de trabalho, dado pela sazonalidade na grande maioria das culturas agrícolas brasileiras. Além disso, é possível que os ocupados por mais tempo esteja em setores da pecuária de corte, sobretudo.

No que diz respeito à escolaridade dos ocupados, apesar de ser um setor de atividade econômica caracterizado por atividades de campo, os resultados apresentados na tabela 01 
conferem melhora substancial na escolaridade dos ocupados, uma vez que, no ano 2000, $85,53 \%$ dos ocupados eram sem instrução ou tinham ensino fundamental incompleto, reduzindo-se esse percentual para 49,75\%, em 2015. Além disso, elevam-se os percentuais de ocupados com os melhores níveis de instruçáo formal, sobretudo para a faixa de ensino médio completo e superior incompleto que sai de 3,64\%, em 2000, para $23,59 \%$, em 2015. Já aqueles com curso superior de formação, registravam-se $1,09 \%$ no primeiro e passou a registrar-se $2,33 \%$ no último ano, resultados que convergem a outros estudos (HOFFMANN \& NEY, 2004; SILVA FILHO, 2013; SANTOS \& RODRIGUES, 2015).

Cresce a participação relativa da regiáo Norte do país que sai de 2,0\% no ano 2000 para $6,10 \%$ no ano de 2015 . Além desta regiáo, o Nordeste e o Centro-oeste elevam suas participaçóes, em detrimento de redução no Sudeste e no Sul do país. A região Nordeste saiu de $12,69 \%$, no ano 2000, para $16,13 \%$, no ano de 2015. Já o Centro-oeste registrava $11,75 \%$ no ano 2000 , e, elevou-se para $18,47 \%$, no ano de 2015 . O Sudeste reduziu-se de $57,41 \%$, no primeiro para $43,90 \%$ no último ano. Já o Sul saiu de $16,18 \%$ para 15,40 , sendo essa região a de redução mais leve em termos relativos.

Além disso, apesar de reduzirem-se o número de municípios com remuneração nas maiores faixas salariais (figura 02) ao longo dos anos, a renda média do trabalho dos ocupados na agropecuária brasileira cresceu em termos reais. No ano 2000 a renda média do trabalho no setor era de $R \$ 1.061,80$ e passou para $R \$ 1.712,98$ no último ano em tela. $\mathrm{O}$ crescimento na renda média na agropecuária brasileira pode resultar da reestruturaçáo produtiva do setor, que eliminou, ao longo dos anos, postos de trabalho mal remunerados, por serem eles em sua maioria de atividades de campo baseada na produtividade pelo desempenho físico dos ocupados, passando a criar postos de trabalho mais intensivos em tecnologia e com uso de recursos técnicos melhores, o que resulta, também, da configuração da educaçáo formal da força de trabalho vista nesta tabela.

\section{Resultados e discussóes}

No Brasil, o mercado formal de trabalho agropecuário apresenta fortes discrepâncias salariais, sendo estas elevadas quando se mensura pelas características socioeconômicas e demográficas dos indivíduos. Nesse sentido, as tabelas que se seguem apresentam dados sobre os diferenciais de rendimento do trabalho no setor agropecuário, a partir de regressóes quantílicas, para os anos de 2000, 2005,2010 e 2015. A princípio, é possível verificar que todas as variáveis contidas nas tabelas em todos os anos foram significativas estatisticamente a $1 \%$.

Os resultados alcançados pela tabela 02 revelam que, a variável sexo tem forte influência sobre as disparidades nos rendimentos do trabalho no setor agropecuário formal brasileiro (CUNHA, 2008; SANTOS et al., 2010). Os resultados apontados no quartil $50^{\circ}$ da distribuição dos rendimentos (mediana) mostram que, em 2000, a diferença salarial entre homens e mulheres era de $16 \%$ em favor dos homens. Essa desigualdade persistiu no ano de 2005, registrando um percentual de $19 \%$. Apesar da leve reduçáo na diferença salarial por sexo, em 2010, essa desigualdade salarial se elevou bastante em 2015, para $22 \%$. Ademais, é possível ainda verificar que, o rendimento do trabalho cresce com a idade, mas de forma decrescente. 
Todavia, estes resultados convergem a vários trabalhos que abordam tal discursão na literatura, os quais mostram que os rendimentos dos homens são mais elevados dos que os recebidos pelas mulheres no mercado de trabalho brasileiro. Maciel \& Oliveira (2017), por exemplo, analisando a desigualdade de rendimentos entre trabalhadores formais e por conta própria no Brasil, entre 2000 e 2010, a partir de regressóes quantílicas, evidenciam um maior nível de desigualdades salarial contra as mulheres. Ademais, o aumento da segmentação na base da distribuição é mais grave para o trabalho por conta própria feminina.

Tabela 02: Impactos das características socioeconômicas e demográficas sobre os diferenciais de rendimentos do trabalho no setor agropecuário formal brasileiro - 2000/2015: Mediana

\begin{tabular}{|c|c|c|c|c|}
\hline \multirow{2}{*}{ Coeficientes } & 2000 & 2005 & 2010 & 2015 \\
\hline & Estimativa & Estimativa & Estimativa & Estimativa \\
\hline \multirow{2}{*}{ (Intercepto) } & $6,390^{* * *}$ & $6,719^{* * *}$ & $7,450^{* * *}$ & $6,561^{* * *}$ \\
\hline & $(0,004)$ & $(0,003)$ & $(0,003)$ & $(0,003)$ \\
\hline \multirow{2}{*}{ Sexo (masculino) } & $0,156^{* * *}$ & $0,189^{* * *}$ & $0,180^{* * *}$ & $0,221^{* * *}$ \\
\hline & $(0,001)$ & $(0,001)$ & $(0,001)$ & $(0,001)$ \\
\hline \multirow{2}{*}{ Idade } & $0,021^{* * *}$ & $0,019^{* * *}$ & $0,008^{* * *}$ & $0,019^{* * *}$ \\
\hline & $(0,000)$ & $(0,000)$ & $(0,000)$ & $(0,000)$ \\
\hline \multirow{2}{*}{ Idade2 } & $0,000^{* * *}$ & $0,000^{* * *}$ & $0,000^{* * *}$ & $0,000^{* * *}$ \\
\hline & $(0,000)$ & $(0,000)$ & $(0,000)$ & $(0,000)$ \\
\hline \multirow{2}{*}{ Pequeno } & $0,200^{* * *}$ & $0,145^{* * *}$ & $0,163^{* * *}$ & $0,168^{* * *}$ \\
\hline & $(0,001)$ & $(0,001)$ & $(0,001)$ & $(0,001)$ \\
\hline \multirow{2}{*}{ Médio } & $0,284^{* * *}$ & $0,232^{* * *}$ & $0,199^{* * *}$ & $0,219^{* * *}$ \\
\hline & $(0,002)$ & $(0,002)$ & $(0,001)$ & $(0,002)$ \\
\hline \multirow{2}{*}{ Grande } & $0,354^{* * *}$ & $0,350^{* * *}$ & $0,326^{* * *}$ & $0,300^{* * *}$ \\
\hline & $(0,002)$ & $(0,001)$ & $(0,004)$ & $(0,002)$ \\
\hline \multirow{2}{*}{ Maisde1a2 } & $0,057^{* * *}$ & $0,047^{* * *}$ & $0,022^{* * *}$ & $0,063^{* * *}$ \\
\hline & $(0,003)$ & $(0,001)$ & $(0,000)$ & $(0,001)$ \\
\hline \multirow{2}{*}{ Maisde2a3 } & $0,083^{* * *}$ & $0,098^{* * *}$ & $0,096^{* * *}$ & $0,134^{* * *}$ \\
\hline & $(0,002)$ & $(0,003)$ & $(0,002)$ & $(0,002)$ \\
\hline \multirow{2}{*}{ Maisde3a5 } & $0,117^{* * *}$ & $0,145^{* * *}$ & $0,170^{* * *}$ & $0,179^{* * *}$ \\
\hline & $(0,003)$ & $(0,001)$ & $(0,002)$ & $(0,001)$ \\
\hline \multirow{2}{*}{ Maisde 5a10 } & $0,183^{* * *}$ & $0,200^{* * *}$ & $0,191^{* * *}$ & $0,239^{* * *}$ \\
\hline & $(0,003)$ & $(0,002)$ & $(0,001)$ & $(0,002)$ \\
\hline \multirow{2}{*}{ Maisde10 } & $0,251^{* * *}$ & $0,305^{* * *}$ & $0,309^{* * *}$ & $0,343^{* * *}$ \\
\hline & $(0,002)$ & $(0,002)$ & $(0,007)$ & $(0,001)$ \\
\hline \multirow{2}{*}{ Fundcompmedinc } & $0,110^{* * *}$ & $0,067^{* * *}$ & $0,018^{* * *}$ & $0,045^{* * *}$ \\
\hline & $(0,002)$ & $(0,001)$ & $(0,000)$ & $(0,001)$ \\
\hline
\end{tabular}




\begin{tabular}{lcc|c|c}
\hline \multirow{2}{*}{ Coeficientes } & 2000 & 2005 & 2010 & 2015 \\
\cline { 2 - 5 } & Estimativa & Estimativa & Estimativa & Estimativa \\
\hline \multirow{2}{*}{ Medcompsupinc } & $0,410^{* * *}$ & $0,286^{* * *}$ & $0,163^{* * *}$ & $0,126^{* * *}$ \\
& $(0,003)$ & $(0,002)$ & $(0,002)$ & $(0,001)$ \\
\hline \multirow{2}{*}{ Supcomp } & $0,736^{* * *}$ & $0,890^{* * *}$ & $0,789^{* * *}$ & $0,698^{* * *}$ \\
& $(0,003)$ & $(0,002)$ & $(0,002)$ & $(0,003)$ \\
\hline \multirow{2}{*}{ NO } & $0,220^{* * *}$ & $0,147^{* * *}$ & $0,084^{* * *}$ & $0,165^{* * *}$ \\
& $(0,003)$ & $(0,001)$ & $(0,001)$ & $(0,001)$ \\
\hline \multirow{2}{*}{ SE } & $0,258^{* * *}$ & $0,207^{* * *}$ & $0,194^{* * *}$ & $0,229^{* * *}$ \\
& $(0,002)$ & $(0,001)$ & $(0,001)$ & $(0,001)$ \\
\hline \multirow{2}{*}{ SU } & $0,292^{* * *}$ & $0,265^{* * *}$ & $0,187^{* * *}$ & $0,298^{* * *}$ \\
& $(0,002)$ & $(0,002)$ & $(0,001)$ & $(0,001)$ \\
\hline \multirow{2}{*}{ CO } & $0,401^{* * *}$ & $0,487^{* * *}$ & $0,398^{* * *}$ & $0,487^{* * *}$ \\
& $(0,002)$ & $(0,001)$ & $(0,001)$ & $(0,002)$ \\
\hline
\end{tabular}

Fonte: elaboração própria a partir de microdados da RAIS/ME

Nota: $\left.{ }^{* * *}\right)$ significância de $1 \%$. (Erro padrão entre parênteses).

Ainda no quartil $50^{\circ}$ da distribuição (mediana), destaca-se também a desigualdade dos rendimentos do trabalho no setor agropecuário pelo tamanho do estabelecimento. Conforme a tabela 02, as maiores disparidades de renda no setor são registradas no grande estabelecimento. Em 2000, um ocupado neste estabelecimento ganhava $35 \%$ a mais de que uma pessoa ocupada no microestabelecimento. Como observado, essa desigualdade salarial vai se reduzindo nos demais anos, mas mantem-se ainda elevada, chegando a registrar um percentual de 30\% em 2015.

A diferença salarial agropecuária também é ratificada pelo tempo de permanência no emprego. Os dados mostram que os retornos salariais são crescentes à medida que aumento o tempo de permanência no emprego. Os que ficam mais de 10 anos em seus postos de trabalho tinham salários de $25 \%$ superiores àqueles que ficavam menos de um ano, em 2000. Essa desigualdade se eleva do decorrer dos anos, com destaque especial em 2015, com $34 \%$ (quartil 50\%/Tabela 02).

Os resultados relacionados ao tempo de permanência no emprego mostram que em todas as faixas de tempo selecionadas, o logaritmo do salário é sempre maior do que para àqueles que ficam menos de um ano em seus postos de trabalhos, conforme vistos também no trabalho de Silva Filho et al. (2017).

É possível ainda perceber a forte influência da variável escolaridade sobre os diferenciais de rendimentos dos ocupados formais agropecuária. Os coeficientes no $50^{\circ}$ quartil (mediana) indicam que em todas as faixas de escolaridade, o salário é superior àqueles auferidos por ocupados sem instrução ou com ensino fundamental incompleto, com destaques especiais nos anos de 2000 e 2005, para os que tinham superior completo que registraram diferenciais de 74\% e 89\%, respectivamente. Essas disparidades apresentaram 
reduções nos demais anos, mas mantendo percentuais ainda elevados (79\%, em 2010; e, 70\%, em 2015).

Ademais, é possível ver ainda neste quartil as disparidades de renda por região de ocupação. Os dados da tabela chamam atenção para o coeficiente dos diferenciais de rendimentos dos ocupado no Centro-Oeste que ganhava $40 \%$ a mais do que àqueles ocupado no Nordeste, em 2000. Essa disparidade aumenta para 48\%, no ano de 2005 , e se reduz para $40 \%$ em 2010. No ano de 2015, a desigualdade salarial é substancial, chegando a registrar um percentual de $49 \%$.

$\mathrm{Na}$ Tabela 03 é possível observar os rendimentos do trabalho do setor agropecuário no $3^{\circ}$ quartil da distribuição. Nesse quartil, os diferenciais de rendimentos entre homens e mulheres são mais elevados quando se compara aos percentuais registrados na mediana e $90^{\circ}$ percentil. A diferença do salário entre homens e mulheres, aqui, eram mais elevadas em favor do sexo masculino. Verifica-se que os homens ganhavam $19 \%$ a mais que as mulheres, em 2000. Essa disparidade aumenta nos anos de 2005 e 2010 para 28\% e 31\%. Em 2015, houve uma redução na desigualdade de rendimentos por sexo, chegando a registrar um percentual de $28 \%$. Ademais, a idade nesse quartil, tem mais influência na desigualdade dos rendimentos do trabalho no setor.

Usando regressões quantílicas, Silva Filho et al. (2017) evidenciam que as maiores desigualdades de rendimentos por sexo no mercado formal da economia cearense foram também registradas no quartil $75^{\circ}$ da distribuição, quando comparados aos demais quartis. Os coeficientes mostram que, em 2000, por exemplo, os homens ganhavam 44,8\% a mais que as mulheres.

Tabela 03: Impactos das características socioeconômicas e demográficas sobre os diferenciais de rendimentos do trabalho no setor agropecuário formal Brasileiro - 2000/2015: 3º Quartil

\begin{tabular}{lccccc}
\hline \multirow{2}{*}{ Coeficientes } & 2000 & 2005 & 2010 & 2015 \\
\cline { 2 - 5 } (Intercepto) & Estimativa & Estimativa & Estimativa & Estimativa \\
\hline \multirow{2}{*}{ Sexo } & $6,561^{* * *}$ & $6,800^{* * *}$ & $7,260^{* * *}$ & $6,706^{* * *}$ \\
& $(0,005)$ & $(0,005)$ & $(0,006)$ & $(0,006)$ \\
\hline \multirow{2}{*}{ Idade } & $0,191^{* * *}$ & $0,288^{* * *}$ & $0,307^{* * *}$ & $0,280^{* * *}$ \\
& $(0,002)$ & $(0,001)$ & $(0,001)$ & $(0,001)$ \\
\hline \multirow{2}{*}{ Idade2 } & $0,024^{* * *}$ & $0,024^{* * *}$ & $0,024^{* * *}$ & $0,023^{* * *}$ \\
& $(0,000)$ & $(0,000)$ & $(0,000)$ & $(0,000)$ \\
\hline \multirow{2}{*}{ Pequeno } & $0,000^{* * *}$ & $0,000^{* * *}$ & $0,000^{* * *}$ & $0,000^{* * *}$ \\
& $(0,000)$ & $(0,000)$ & $(0,000)$ & $(0,000)$ \\
\hline \multirow{2}{*}{ Médio } & $0,158^{* * *}$ & $0,163^{* * *}$ & $0,146^{* * *}$ & $0,168^{* * *}$ \\
& $(0,001)$ & $(0,002)$ & $(0,002)$ & $(0,002)$ \\
\hline
\end{tabular}




\begin{tabular}{|c|c|c|c|c|}
\hline \multirow{2}{*}{ Coeficientes } & 2000 & 2005 & 2010 & 2015 \\
\hline & Estimativa & Estimativa & Estimativa & Estimativa \\
\hline \multirow{2}{*}{ Grande } & $0,321^{* * *}$ & $0,305^{* * *}$ & $0,305^{* * *}$ & $0,271^{* * *}$ \\
\hline & $(0,002)$ & $(0,001)$ & $(0,001)$ & $(0,001)$ \\
\hline \multirow{2}{*}{ Maisde1a2 } & $0,052^{* * *}$ & $0,018^{* * *}$ & $0,024^{* * *}$ & $0,043^{* * *}$ \\
\hline & $(0,002)$ & $(0,001)$ & $(0,001)$ & $(0,002)$ \\
\hline \multirow{2}{*}{ Maisde2a3 } & $0,071^{* * *}$ & $0,061^{* * *}$ & $0,075^{* * *}$ & $0,102^{* * *}$ \\
\hline & $(0,003)$ & $(0,003)$ & $(0,002)$ & $(0,002)$ \\
\hline \multirow{2}{*}{ Maisde3a5 } & $0,118^{* * *}$ & $0,096^{* * *}$ & $0,130^{* * *}$ & $0,149^{* * *}$ \\
\hline & $(0,003)$ & $(0,001)$ & $(0,002)$ & $(0,002)$ \\
\hline \multirow{2}{*}{ Maisde5a10 } & $0,167^{* * *}$ & $0,169^{* * *}$ & $0,189^{* * *}$ & $0,229^{* * *}$ \\
\hline & $(0,001)$ & $(0,003)$ & $(0,002)$ & $(0,002)$ \\
\hline \multirow{2}{*}{ Maisde10 } & $0,236^{* * *}$ & $0,266^{* * *}$ & $0,293^{* * *}$ & $0,300^{* * *}$ \\
\hline & $(0,004)$ & $(0,001)$ & $(0,002)$ & $(0,002)$ \\
\hline \multirow{2}{*}{ Fundcompmedinc } & $0,115^{* * *}$ & $0,075^{* * *}$ & $0,042^{* * *}$ & $0,043^{* * *}$ \\
\hline & $(0,001)$ & $(0,001)$ & $(0,001)$ & $(0,001)$ \\
\hline \multirow{2}{*}{ Medcompsupinc } & $0,427^{* * *}$ & $0,319^{* * *}$ & $0,183^{* * *}$ & $0,130^{* * *}$ \\
\hline & $(0,003)$ & $(0,002)$ & $(0,001)$ & $(0,001)$ \\
\hline \multirow{2}{*}{ Supcomp } & $0,680^{* * *}$ & $0,861^{* * *}$ & $0,817^{* * *}$ & $0,716^{* * *}$ \\
\hline & $(0,002)$ & $(0,002)$ & $(0,004)$ & $(0,003)$ \\
\hline \multirow{2}{*}{$\mathrm{NO}$} & $0,231^{* * *}$ & $0,255^{* * *}$ & $0,159^{* * *}$ & $0,221^{* * *}$ \\
\hline & 0,004 & $(0,002)$ & $(0,003)$ & $(0,003)$ \\
\hline \multirow{2}{*}{ SE } & $0,260^{* * *}$ & $0,292^{* * *}$ & $0,287^{* * *}$ & $0,266^{* * *}$ \\
\hline & 0,002 & $(0,001)$ & $(0,002)$ & $(0,002)$ \\
\hline \multirow{2}{*}{ SU } & $0,254^{* * *}$ & $0,285^{* * *}$ & $0,240^{* * *}$ & $0,290^{* * *}$ \\
\hline & $(0,002)$ & $(0,001)$ & $(0,002)$ & $(0,002)$ \\
\hline \multirow{2}{*}{$\mathrm{CO}$} & 0,350 & $0,470^{* * *}$ & $0,392^{* * *}$ & $0,439^{* * *}$ \\
\hline & $(0,003)$ & $(0,002)$ & $(0,002)$ & $(0,002)$ \\
\hline
\end{tabular}

Fonte: elaboração própria a partir de microdados da RAIS/ME

Nota: $\left.{ }^{* * *}\right)$ significância de $1 \%$. (Erro padrão entre parênteses).

No que se refere ao tamanho do estabelecimento, verifica-se que o diferencial de rendimentos é mais acentuado no grande estabelecimento agropecuário. Os dados revelam que, em 2000, uma pessoa ocupada neste estabelecimento recebia $32 \%$ a mais que aqueles ocupados no microestabelecimento. Essa desigualdade foi-se reduzindo nos demais anos: em 2005 e 2010, caiu para de 31\%, e, em 2015, essa redução foi mais acentuada, chegando a $27 \%$, conforme os dados apresentados na tabela 03 , no $3^{\circ}$ quartil. 
Ademias observa-se que no $3^{\circ}$ quartil, os retornos salariais são crescentes em relação às faixas de tempo no emprego. Verifica-se que, no ano de 2000, quem ficava mais de 10 anos ocupado no mesmo posto de trabalho auferia uma renda de $24 \%$ a mais do que àqueles que permaneciam menos de um ano em seu emprego. Nos demais anos, essa disparidade foi-se elevando, com destaque especial em 2015 que registraram diferenciais de rendimentos de $30 \%$.

Além disso, destaca-se a desigualdade de renda pela escolaridade do ocupado formal no setor agropecuário, principalmente aqueles com ensino superior completo. Os dados mostram que no ano de 2000, quem tinha superior completo auferia uma renda de $68 \%$ a mais do que uma pessoa sem instrução ou com ensino fundamental incompleto. Em 2005 , essa diferença aumenta substancialmente para $86 \%$. É possível notar reduções dessa desigualdade, mas ainda mandando elevados percentuais: em 2010, com $82 \%$ e, em 2015 , com $72 \%$.

Silva Filho et al. (2017), mostram os salários dos indivíduos em qualquer faixa de escolaridade apresentam maior logaritmos dos rendimentos do trabalho quando comparados aos rendimentos dos trabalhadores analfabetos. Conforme Soares (2009), quanto maior for os níveis de instrução dos trabalhadores (escolaridade), mais significativos são os retornos salariais.

A questáo da regiáo de ocupação também se mostrou relevante para explicar os diferenciais de rendimentos no setor agropecuário. Os dados apresentados no $3^{\circ}$ quartil evidenciaram que as maiores discrepâncias salarias são registradas no Centro-Oeste, quando comparadas ao Nordeste. Isto é, os ocupados na agropecuária no Centro-Oeste recebiam $35 \%$ a mais que os ocupados na região Nordeste do Brasil.

Os resultados da Tabela 04 mostram as diferenças de salários no setor agropecuário no $90^{\circ}$ percentil da distribuição. Como pode ser visualizada, os resultados convergem à literatura brasileira, mostrando que os salários dos homens são mais elevados que os das mulheres. Em 2000, o salário de um homem era de 18\% maior dos que o salário de uma mulher. Essa desigualdade foi aumentando em 2005 (25\%) e 2010 (36\%) e, no ano de 2015 , apesar de ainda elevada, registrou uma redução para $23 \%$.

Tabela 04: Impactos das características socioeconômicas e demográficas sobre os diferenciais de rendimentos do trabalho no setor agropecuário formal Brasileiro - 2000/2015: 90º Percentil

\begin{tabular}{l|c|c|c|c}
\hline \multirow{2}{*}{ Coeficientes } & 2000 & 2005 & 2010 & 2015 \\
\cline { 2 - 5 } & Estimativa & Estimativa & Estimativa & Estimativa \\
\hline \multirow{2}{*}{ Intercepto) } & $6,833^{* * *}$ & $7,206^{* * *}$ & $7,684^{* * *}$ & $7,169^{* * *}$ \\
& $(0,008)$ & $(0,007)$ & $(0,010)$ & $(0,009)$ \\
\hline \multirow{2}{*}{ Sexo } & $0,183^{* * *}$ & $0,249^{* * *}$ & $0,256^{* * *}$ & $0,232^{* * *}$ \\
& $(0,002)$ & $(0,002)$ & $(0,003)$ & $(0,002)$ \\
\hline
\end{tabular}




\begin{tabular}{|c|c|c|c|c|}
\hline \multirow{2}{*}{ Coeficientes } & 2000 & 2005 & 2010 & 2015 \\
\hline & Estimativa & Estimativa & Estimativa & Estimativa \\
\hline \multirow{2}{*}{ Idade } & $0,022^{* * *}$ & $0,025^{* * *}$ & $0,022^{* * *}$ & $0,018^{* * *}$ \\
\hline & $(0,000)$ & $(0,000)$ & $(0,001)$ & $(0,000)$ \\
\hline \multirow{2}{*}{ Idade $^{2}$} & $0,000^{* * *}$ & $0,000^{* * *}$ & $0,000^{* * *}$ & $0,000^{* * *}$ \\
\hline & $(0,000)$ & $(0,000)$ & $(0,000)$ & $(0,000)$ \\
\hline \multirow{2}{*}{ Pequeno } & $0,156^{* * *}$ & $0,125^{* * *}$ & $0,121^{* * *}$ & $0,151^{* * *}$ \\
\hline & $(0,002)$ & $(0,002)$ & $(0,002)$ & $(0,002)$ \\
\hline \multirow{2}{*}{ Médio } & $0,269^{* * *}$ & $0,187^{* * *}$ & $0,203^{* * *}$ & $0,199^{* * *}$ \\
\hline & $(0,003)$ & $(0,002)$ & $(0,002)$ & $(0,002)$ \\
\hline \multirow{2}{*}{ Grande } & $0,302^{* * *}$ & $0,233^{* * *}$ & $0,225^{* * *}$ & $0,217^{* * *}$ \\
\hline & $(0,002)$ & $(0,002)$ & $(0,002)$ & $(0,002)$ \\
\hline \multirow{2}{*}{ Maisde1a2 } & $0,034^{* * *}$ & $-0,003^{* * *}$ & $0,014^{* * *}$ & $0,020^{* * *}$ \\
\hline & $(0,002)$ & $(0,001)$ & $(0,002)$ & $(0,002)$ \\
\hline \multirow{2}{*}{ Maisde2a3 } & $0,050^{* * *}$ & $0,021^{* * *}$ & $0,064^{* * *}$ & $0,072^{* * *}$ \\
\hline & $(0,002)$ & $(0,002)$ & $(0,003)$ & $(0,003)$ \\
\hline \multirow{2}{*}{ Maisde3a5 } & $0,099^{* * *}$ & $0,053^{* * *}$ & $0,112^{* * *}$ & $0,136^{* * *}$ \\
\hline & $(0,003)$ & $(0,002)$ & $(0,003)$ & $(0,003)$ \\
\hline \multirow{2}{*}{ Maisde5a10 } & $0,148^{* * *}$ & $0,104^{* * *}$ & $0,207^{* * *}$ & $0,243^{* * *}$ \\
\hline & $(0,002)$ & $(0,003)$ & $(0,003)$ & $(0,004)$ \\
\hline \multirow{2}{*}{ Maisde10 } & $0,251^{* * *}$ & $0,228^{* * *}$ & $0,343^{* * *}$ & $0,426^{* * *}$ \\
\hline & $(0,003)$ & $(0,003)$ & $(0,006)$ & $(0,006)$ \\
\hline \multirow{2}{*}{ Fundcompmedinc } & $0,138^{* * *}$ & $0,070^{* * *}$ & $0,035^{* * *}$ & $0,035^{* * *}$ \\
\hline & $(0,003)$ & $(0,001)$ & $(0,002)$ & $(0,002)$ \\
\hline \multirow{2}{*}{ Medcompsupinc } & $0,423^{* * *}$ & $0,363^{* * *}$ & $0,195^{* * *}$ & $0,132^{* * *}$ \\
\hline & $(0,004)$ & $(0,002)$ & $(0,002)$ & $(0,002)$ \\
\hline \multirow{2}{*}{ Supcomp } & $0,616^{* * *}$ & $0,796^{* * *}$ & $0,765^{* * *}$ & $0,660^{* * *}$ \\
\hline & $(0,002)$ & $(0,001)$ & $(0,005)$ & $(0,003)$ \\
\hline \multirow{2}{*}{ NO } & $0,214^{* * *}$ & $0,152^{* * *}$ & $0,084^{* * *}$ & $0,122^{* * *}$ \\
\hline & $(0,006)$ & $(0,003)$ & $(0,004)$ & $(0,004)$ \\
\hline \multirow{2}{*}{ SE } & $0,228^{* * *}$ & $0,191^{* * *}$ & $0,218^{* * *}$ & $0,174^{* * *}$ \\
\hline & $(0,002)$ & $(0,003)$ & $(0,002)$ & $(0,003)$ \\
\hline \multirow{2}{*}{ SU } & $0,207^{* * *}$ & $0,147^{* * *}$ & $0,132^{* * *}$ & $0,171^{* * *}$ \\
\hline & $(0,003)$ & $(0,003)$ & $(0,003)$ & $(0,003)$ \\
\hline \multirow{2}{*}{$\mathrm{CO}$} & $0,282^{* * *}$ & $0,301^{* * *}$ & $0,263^{* * *}$ & $0,292^{* * *}$ \\
\hline & $(0,003)$ & $(0,003)$ & $(0,003)$ & $(0,003)$ \\
\hline
\end{tabular}

Fonte: elaboração própria a partir de microdados da RAIS/ME 
Nota: $\left.{ }^{* * *}\right)$ significância de $1 \%$. (Erro padrão entre parênteses).

Pelos dados, fica evidente, ainda pela Tabela 04 que, em 2000, os indivíduos ocupados no grande estabelecimento agropecuário apresentaram salários superiores em $30 \%$ àqueles que estavam no microestabelecimento. Nos anos seguintes, percebe-se que essa disparidade salarial vai se reduzindo, principalmente em 2015, para 28\%. Nessa categoria, apesar de ter registro de reduçóes, foi a que se encontraram os maiores diferenciais de rendimentos do trabalho.

No tocante ao tempo de permanência do emprego, percebe-se que as maiores disparidades são observadas da faixa mais de dez anos. Isto é, os indivíduos que estavam ocupados a mais de dez anos auferiam rendimentos $25 \%$ a mais em relação àqueles ocupados a menos de um ano. Nota-se que nos demais anos essa disparidade se eleva, chegando a registrar, em 2015, percentual de 43\%. Isso mostra que quanto maior for o tempo de permanência de um indivíduo no emprego maior será a sua remuneração, resultado este que pode estar relacionada à sua experiência obtida ao longo dos anos.

É possível ainda verificar, que a escolaridade também registrou grau elevado da discrepância nos rendimentos do trabalho dos ocupados no setor agropecuário: nos anos de 2000, os indivíduos que tinham ensino superior completo recebiam $67 \%$ a mais do que aqueles sem instrução ou com ensino fundamental incompleto; e, em 2005, essa disparidade elevou-se para 80\%. Percebe-se, ainda, que, mesmo com redução, em 2010 (77\%) e 2015 (66\%), ela foi acentuadamente elevada em todas as faixas de escolaridade.

A região de ocupação também desempenha papel importante para explicar a variação da renda do trabalho formal agropecuário brasileiro. Os resultados mostram que todos os ocupados formais do setor agropecuário em qualquer região do Brasil, recebiam salários superiores aos ocupados no Nordeste. As maiores disparidades foram registradas no CentroOeste, onde os ocupados desta região recebiam $28 \%$ a mais que um ocupado no Nordeste, em 2000. Em 2005, essa diferença se elevou para 30\%, e, em 2010 e 2015, apesar de ainda elevadas, registrou-se reduçóes quanto comparado ao ano anterior.

Analisando as disparidades regionais de renda no Brasil, a partir da utilização de regressóes quantílicas, Silveira Neto \& Campêlo (2003) constataram que as maiores disparidades regionais afetam principalmente à região nordestina, sobretudo, aos mais pobres das regiōes metropolitanas do Nordeste do país. Conforme Machado \& Mata (2005), as regióes economicamente mais desenvolvidas asseguram melhores salários e menores desigualdades salarias entre os ocupados do mercado formal de trabalho brasileiro.

\section{Consideraçôes Finais}

O objetivo deste artigo foi analisar as disparidades de rendimentos do trabalho entre os ocupados na agropecuária brasileira, seguindo uma análise temporal, e observando os efeitos das características socioeconômicas e demográficas dos ocupados sobre os diferenciais de rendimento do trabalho ao longo da distribuição condicional dos salários. Pelas estatísticas aqui apresentadas, elevam-se o número de ocupados em todas as regióes brasileiras ao logo dos anos, em detrimento de mudanças na participação relativa de cada uma delas. Além disso, a reestruturação da agropecuária nacional impactou sobre a renda do 
trabalho, tendo-se reduzido o número de municípios com renda média nas maiores faixas e elevando-se o número nas faixas de renda intermediária.

Os resultados mostram redução relativa da concentração de postos de trabalho na agropecuária brasileira nas regióes Sudeste e Sul em detrimento da elevação da participação das regióes Nordeste, Norte e Centro-oeste, oriundos ainda dos resultados da expansão da fronteira agropecuária nacional. Ademais, a participação de mulheres ocupadas no setor cresceu relativamente ao longo dos anos, em detrimento da redução relativa da participação masculina. Além disso, a distribuição dos postos de trabalho por tamanho do estabelecimento e por tempo de permanência no emprego parece não ter registrado mudanças substanciais, sendo concentrados ocupados no microestabelecimento e tendo elevada rotatividade nos postos de trabalho em todos os anos em análises. Porém, é importante destacar a melhora da escolaridade dos ocupados formais na agropecuária brasileira, bem como a elevação da renda média no trabalho ao longo dos anos.

No que diz respeito às estimaçóes por regressóes quantílicas, os dados mostram que, a desigualdade de renda segundo o sexo se eleva ao longo dos anos, tanto na mediana quanto no terceiro quartil e no nonagésimo percentil da distribuição da renda do trabalho. Ou seja, apesar de elevar a participação das mulheres ocupadas na agropecuária brasileira, ao longo da distribuição condicional dos salários, os homens apresentam vantagens sobre a remuneração no setor em tela e mostrou-se crescente ao longo dos anos.

Ademais, ao longo da distribuição dos salários, o efeito do tamanho do estabelecimento sobre a renda dos ocupados se reduz em todos os quantís da distribuição da renda do trabalho, ao passo que os efeitos do tempo de permanência no emprego crescem. Ou seja, na mediana, no terceiro quartil e no nonagésimo percentil, ao longo dos anos em tela, os que ficavam ocupados mais de um a dois anos; mais de dois a três anos; mais de três a cinco anos; mais de cinco a dez anos; e, mais de dez anos, recebiam renda do trabalho superior a quem ficava menos de um ano ocupado, elevando-se esses diferenciais no ano último ano, comparativamente aos coeficientes registrados no primeiro.

No que diz respeito aos retornos à escolaridade, é oportuno destacar que, na mediana, reduzem-se, ao longo dos anos, os efeitos da elevação da educação formal sobre os rendimentos do trabalho dos ocupados na agropecuária brasileira, mesmo que em todos os anos, as faixas mais altas de remuneração apresentaram coeficientes mais elevados, mostrando que os mais escolarizados recebem maiores salários em detrimento dos menos escolarizados. No terceiro quartil e no nonagésimo percentil da distribuição a renda do trabalho formal na agropecuária brasileira, também se registrou menores coeficientes de retornos à escolaridade para as primeiras faixas e somente aqueles com curso superior de formação elevou-se o valor do coeficiente no ano de 2015, comparativamente ao ano de 2000.

No que diz respeito à região de ocupação, na mediana e no terceiro quartil as regióes Norte e Sudeste registraram coeficientes relativamente constantes entre os anos, mas com renda superior aos ocupados no Nordeste em todos eles. Já as regióes Sul e Centro-oeste apresentaram coeficientes crescentes, mostrando elevar a disparidade ao longo dos anos, na distribuição de renda entre os ocupados nestas regióes e um ocupado no Nordeste. No nonagésimo percentil da distribuição de renda, todas as regiōes em apreço apresentaram 
retornos salariais mais elevados aos ocupados na agropecuária do que um ocupado no Nordeste, mas com coeficientes sem apresentar variaçóes significativas ao longo dos anos.

Diante disso, fica, pois, evidente que as características socioeconômicas e demográficas afetam os diferenciais de rendimentos do trabalho no setor agropecuário brasileiro e essas disparidades, em alguns casos, elevam-se ao longo dos anos e da distribuiçấo condicional dos salários. Para mensura melhor estes efeitos, como sugestáo, é preciso ampliar as pesquisas no setor, dividindo-o por atividade, características da produçáo regional, bem como de questôes relacionadas às aptidôes dos ocupados ao desenvolvimento das atividades agropecuária do país.

\section{Referências}

BATISTA, N. N. F; CACCIAMALI, M. C. Diferencial de salários entre homens e mulheres segundo a condição de migraçáo. Revista Brasileira de Estudos de População. Rio de Janeiro, v. 26, n. 1, p. 97-115, jan./jun. 2009.

BUCHINSKY, M.. Recent advances in quantile regression models: a practical guideline for empirical research. Journal of human resources, p. 88-126, 1998.

CASARI, P.; BACHA, C. J. C. Modernização da agropecuária brasileira e seus impactos sobre os salários e o desemprego: período de 1998 a 2007. Texto para discursão IPEA. Rio de Janeiro, 2010.

COELHO, A. M.; CORSEUIL, C. H. Diferenciais salariais no Brasil: um breve panorama. Texto para discursão IPEA. Rio de Janeiro, 2002.

CUNHA, M. S. Evoluçáo do emprego e dos salários no setor agrícola brasileiro: trabalho temporário e permanente. Rev. de Economia Agrícola, v. 56, n. 1, p. 89-101, 2009.

CUNHA, M. S. Os empregados da agricultura brasileira: diferenciais e determinantes salariais. RESR, vol. 46, nº 03, p. 597-621, 2008.

FREGUGLIA, R. da S.; PROCÓPIO, T. S. Efeitos da mudança de emprego e da migração interestadual sobre os salários no brasil formal: evidências a partir de dados em painel. Pesquisa e planejamento econômico, v. 43, n. 2, agosto 2013.

HOFFMANN, R. Distribuição da renda agrícola e sua contribuição para a desigualdade de renda no Brasil. Revista de Política Agrícola, Ano XX, v. 2, p. 6-22, 2011.

HOFFMANN, R; NEY, M. G. Desigualdade, escolaridade e rendimentos na agropecuária, indústria e serviços, de 1992 a 2002. Economia e Sociedade, v. 13, n. 2 (23), p. 51-79, 2004. 
HOFFMANN, R; SIMÁO, R. C. S. Determinantes do rendimento das pessoas ocupadas em Minas Gerais em 2000: o limiar no efeito da escolaridade e as diferenças entre Mesorregiōes. Nova Economia, v.15, n. 2, p. 35-62, 2005.

JUSTO, W. R. Capital humano diminui desigualdade? Evidências para o Brasil a partir de regressóes quantílicas. Economia e Desenvolvimento, v. 5, n. 2, p. 189-220, 2006.

KOENKER, R.; BASSET, G. Asymptotic theory of least absolute error regression. Journal of the American Statistical Association, v. 73, n. 363, p. 618-22, 1978.

MACHADO, A. F.; OLIVEIRA, A. M. H. C.; ANTIGO, M. Evolução do diferencial de rendimentos entre setor formal e informal no Brasil: o papel das características não observadas. R. Econ. contemp., v. 12, n. 2, p. 355-388, 2008.

MACHADO, J.; MATA, J. Counterfactual decomposition of changes in wage distributions using quantile regression. Journal of Applied Econometrics, v. 20, p. 445465, 2005.

MACIEL, F. T.; OLIVEIRA, A. M. H. Uma decomposição da desigualdade de rendimentos entre trabalho formal e por conta própria no Brasil (2000-2010): evidências a partir de regressóes quantílicas. Pesquisa e Planejamento Econômico, v. 47, n. 3, P. 101136, 2017.

MATOS, R. S.; MACHADO, A. F. Diferencial de rendimentos por cor e sexo no Brasil (1987-2001). Econômica, Rio de Janeiro, v. 8, n. 1, p. 5-27, junho 2006.

NEY, M. G. Origem familiar e desigualdade de renda na agricultura. Pesquisa e planejamento econômico, v.33, n.3, p. 541-572, 2003.

NEY, M. G.; HOFFMANN, R. Desigualdade de renda na agricultura: o efeito da posse da terra. ECONOMIA, v. 4, n. 1, p. 113-152, 2003.

RAMOS, L.; VIEIRA, M. L. Desigualdade de rendimentos no Brasil nas décadas de $80 \mathrm{e}$ 90: evolução e principais determinantes. Texto para discursão IPEA. Rio de Janeiro, 2001.

SANTOS, A.; CASARI, P. Rendimento dos trabalhadores no setor agropecuário no Brasil e na região Centro-Oeste: uma análise a partir da teoria da segmentação. Rev. Des. Regional (REDES), v. 19, n.1, p. 150 - 168, 2014.

SANTOS, G. C.; FONTES, R. M. O; BASTOS, P. M. A.; LIMA, J. B. Mercado de trabalho e rendimento no meio rural brasileiro. Economia Aplicada, v. 14, n. 3, P. 355$379,2010$.

SANTOS, G. C.; FONTES, R. M. O; BASTOS, P. M. A.; LIMA, J. B. Mercado de trabalho e rendimento no meio rural brasileiro. Economia Aplicada, v. 14, n. 3, P. 355$379,2010$. 
SAVEDOFF, W. D. Os diferenciais regionais de salários no Brasil: segmentação versus dinamismo da demanda. Pesq. Plan. Econ., v. 20, n. 3, p. 521-556, 1990.

SILVA FILHO, L. A. de. Mudanças Estruturais, mercado de trabalho e rotatividade no emprego agropecuário no Brasil. RDE - Revista De Desenvolvimento Econômico, ano $\mathrm{XV}, \mathrm{n}^{\circ} 27,2013$.

SILVA FILHO, L. A.; MIYAMOTO, B. C. B.; SANTOS, J. M. Mercado de trabalho e diferenciais de rendimentos no emprego formal no Ceará no período de 2000 a 2014. Rev. Econ. NE, v. 48, n. 4, p. 25-44, 2017.

SILVEIRA NETO, R. M.; CAMPÊLO, A. K. Radiografando as disparidades regionais da renda no Brasil: evidências a partir de regressóes quantílicas. Revista Econômica do Nordeste, v. 34, no 3, p. 359-378, 2003.

SOARES, S. S. D. Simulando - o mundo maravilhoso das distribuiçóes contrafatuais. Texto para discursão IPEA. Brasília, 2001.

SOARES, W. R. F. Diferenças Salariais e Desigualdade de Renda nas Mesorregióes Mineiras: uma Análise a Partir dos Microdados da RAIS Utilizando Regressão Quantílica. Revista Econômica do Nordeste (REN), v. 40, n. 1, p. 31-59, 2009.

STADUTO, J. A. R. Determinação dos salários na agropecuária brasileira - período de 1971 a 1996. Tese (doutorado na área de economia aplicada) - Escola superior de Agropecuária “Luiz de Queiroz”, Universidade de São Paulo, 2002.

VILELA, T.; ARAÚJO, E.; RIBEIRO, E. P. Análise do diferencial de renda do trabalho em 2008 entre diferentes geraçóes de trabalhadores no Brasil. Economia, v.13, n.2, p.385414, 2012. 